\title{
Effects of disclosing hypothetical genetic test results for salt sensitivity on salt restriction behavior
}

This article was published in the following Dove Press journal:

International Journal of General Medicine

13 May 2013

Number of times this article has been viewed

\author{
Taro Takeshima ${ }^{1,2}$ \\ Masanobu Okayama' \\ Masanori Harada ${ }^{3}$ \\ Ryusuke $\mathrm{Ae}^{4}$ \\ Eiji Kajii'
}

'Division of Community and Family Medicine, Center for Community Medicine, Jichi Medical University, Tochigi, Japan; ${ }^{2}$ Department of Healthcare Epidemiology, Kyoto University Graduate School of Medicine and Public Health, Kyoto, Japan; ${ }^{3}$ Department for Support of Rural Medicine, Yamaguchi Grand Medical Center, Yamaguchi, Japan; ${ }^{4}$ Department of General Internal Medicine, Hamasaka Public Hospital, Mikata, Japan
Correspondence: Masanobu Okayama Division of Community and Family Medicine, Center for Community Medicine, Jichi Medical University, Yakushiji 33II-I, Shimotsuke,

Tochigi 329-0498, Japan

$\mathrm{Tel}+8 \mathrm{I} 285587394$

Fax +8I 285440628

Email okayama@jichi.ac.jp
Background: A few studies have explored the effects of disclosure of genetic testing results on chronic disease predisposition. However, these effects remain unclear in cases of hypertension. Reducing salt intake is an important nonpharmacological intervention for hypertension. We investigated the effects of genetic testing for salt sensitivity on salt restriction behavior using hypothetical genetic testing results.

Methods: We conducted a cross-sectional study using a self-completed questionnaire. We enrolled consecutive outpatients who visited primary care clinics and small hospitals between September and December 2009 in Japan. We recorded the patients' baseline characteristics and data regarding their salt restriction behavior, defined as reducing salt intake before and after disclosure of hypothetical salt sensitivity genetic test results. Behavioral stage was assessed according to the five-stage transtheoretical model. After dividing subjects into salt restriction and no salt restriction groups, we compared their behavioral changes following positive and negative test results and analyzed the association between the respondents' characteristics and their behavioral changes.

Results: We analyzed 1562 participants with a mean age of 58 years. In the no salt restriction group, which included patients at the precontemplation, contemplation, and preparation stages, 58.7\% stated that their behavioral stage progressed after a positive test result, although $29.8 \%$ reported progression after a negative result $(P<0.001)$. Conversely, in the salt restriction group, which included patients at the active and maintenance stages, $9.2 \%$ stated that they would quit restricting salt intake following a negative test result, and $2.2 \%$ reported they would quit following a positive result $(P<0.001)$. Age $<65$ years (adjusted odds ratio [OR] 1.74; 95\% confidence interval [CI] 1.12-2.71), female gender (adjusted OR 1.84; CI 1.29-2.62), graduation from college or university (adjusted OR 1.66; CI 1.11-2.49), and desire for genetic testing (adjusted OR 4.53; CI 3.13-6.57) were associated with progression of behavioral stage in the no salt restriction group. Conversely, salt preference (adjusted OR 2.13; CI 1.31-3.49) was associated with quitting salt restriction in the salt restriction group.

Conclusion: Patients in the no salt restriction group show the possibility of progression from the behavioral stage to the action stage after testing positive for salt sensitivity. Conversely, patients in the salt restriction group, particularly those with a salt preference, would quit salt restriction after testing negative.

Keywords: behavioral change model, salt restriction, hypertension, genetic testing

\section{Introduction}

In recent years, gene polymorphisms have been identified in many lifestyle-related diseases, including hypertension, diabetes, and hyperlipidemia. Therefore, application of such genetic test results has become an important issue. ${ }^{1}$ Excessive salt intake is 
associated with increased blood pressure, ${ }^{2}$ and reduced salt intake has been shown to decrease blood pressure. ${ }^{3,4}$ Thus, moderate salt restriction is an important nonpharmacological intervention for hypertension. ${ }^{5}$ This behavioral modification, ie, reducing salt intake, requires strong patient motivation. ${ }^{6}$

Several gene polymorphisms associated with saltsensitive hypertension have been identified. ${ }^{7}$ Patients with these genetic factors are likely to develop hypertension from excessive salt intake. ${ }^{8,9}$ Genetic test results for hypertensionrelated genes are expected to be used to prevent hypertension. Disclosing the results of genetic risk for salt-sensitive hypertension is necessary to motivate patients to modify their salt intake. In the process of behavioral change, feelings about importance and confidence contribute to the general state of readiness to change. ${ }^{10}$ Motivation is defined as an individual's expressed degree of readiness to change. The transtheoretical model of behavioral change assesses an individual's readiness to act on a new health-related behavior, and provides strategies to guide them through the stages of change needed to act on the desired behavior. ${ }^{11}$ In order to be effective, disclosure of the genetic test results needs to affect the transtheoretical model of behavioral change.

A few studies have explored the relationships between genetic risk and behavioral change related to willingness to undergo cancer screening among cancer patients ${ }^{12}$ and to pay for treatment response among depressed individuals. ${ }^{13}$ However, the effects of test result disclosure on salt restriction behavior is unknown. ${ }^{14}$

We evaluated the effects of disclosure of genetic test results using hypothetical scenarios about salt sensitivity genetic testing and examined the factors associated with behavioral modification of salt restriction. Providing individuals with information on genetic risk may not increase their motivation to change their behavior, and may actually decrease their motivation in some cases. ${ }^{15}$ Thus, in this study, hypothetical genetic test results were applied for the sake of safety.

\section{Materials and methods}

In this cross-sectional study, we enrolled consecutive outpatients aged 20 years and older who attended three primary care clinics and two small hospitals in Japan between September and December 2009. The study was approved by the bioethics committee of Jichi Medical University.

\section{Measurements}

We recorded the patients' baseline characteristics and behavioral stages using a questionnaire. We also assessed their behavioral stages after disclosure of hypothetical genetic salt sensitivity test results, which were provided as a positive or negative finding without any counseling. The hypothetical genetic test indicated the presence or absence of risk for salt-sensitivity hypertension.

Baseline characteristics included age, gender, highest level of education (junior high school, high school, college, or university), family history of hypertension, current status of hypertension, history of cerebrovascular and cardiovascular disease, anxiety about hypertension, salt preference ("Do you prefer salty food?'), and desire to undergo genetic testing for salt-sensitivity hypertension.

Behavioral stage was assessed using five questions: "I am not concerned about reducing my salt intake at all" (no intention of salt restriction), "I must reduce my salt intake, but I cannot do it" (have the intention but not prepared for salt restriction), "I am ready to start reducing my salt intake" (prepared for salt restriction in the near future), "I have already reduced my salt intake within the past six months" (successfully altering a behavior for one day to six months), and "I have been reducing my salt intake for more than 6 months" (successfully altering a behavior for more than six months), adopted from a questionnaire based on the transtheoretical model of behavioral change authorized by the Ministry of Health, Labour, and Welfare in Japan. ${ }^{16}$

The transtheoretical model defines the behavioral stages as precontemplation, contemplation, preparation, action, and maintenance. ${ }^{11}$ We defined "precontemplation" as "no intention of salt restriction", "contemplation" as "have the intention but not prepared for salt restriction", "preparation" as "prepared for salt restriction in the near future", "action" as "successfully altering a behavior for one day to six months", and "maintenance" as "successfully altering a behavior for more than six months". We divided the subjects into two groups on the basis of their baseline behavioral stages. The no salt restriction group included patients in the precontemplation, contemplation, and preparation stages, while the salt restriction group included patients in the action and maintenance stages. Thus, patients who had not started to reduce their salt intake were included in the no salt restriction group, while those who had already been reducing their salt intake were included in the salt restriction group.

\section{Recording and defining behavioral changes}

We assessed the patients' behavioral stages before and after disclosure of hypothetical salt sensitivity genetic test results. The patients' behavioral stages before and after disclosure of the hypothetical results in the no salt restriction and 
salt restriction groups were recorded as an upward trend and a quit, respectively. In the no salt restriction group, progression to more than one stage after disclosure was defined as an upward trend. If patients with a baseline behavioral stage of precontemplation progressed to contemplation, preparation, or action stages following disclosure, they were classified as an upward trend. In cases of contemplation and preparation stages at baseline, patients who progressed to the preparation or action stage and progressed to the action stage after disclosure were classified as an upward trend. In the salt restriction group, we asked the patients whether they would continue or quit their salt restriction after receiving the test results. The patients who answered "quit salt restriction" were classified as a "quit" for their behavioral change.

\section{Statistical analysis}

Numerical and categorical data are presented as the mean \pm standard deviation and percentages of the population, respectively. The goals of the salt intake intervention differed between the no restriction and the restriction group; therefore, we performed separate statistical analyses in each group. We compared the differences in behavioral changes following disclosure of positive and negative hypothetical genetic test results using the Chi-square test or Fisher's Exact test. In addition, using univariate logistic regression analysis, crude odds ratios (OR) and $95 \%$ confidence intervals $(\mathrm{CI})$ were calculated to identify factors related to behavioral changes (upward trend and quit). Then, using multivariate logistic analysis for the variables that were significantly related in the univariate analysis and baseline behavioral stages, adjusted ORs (95\% CI) were obtained for the independent factors related to behavioral changes. Analyses were two-sided, with $P<0.05$ considered to be statistically significant. All analyses were performed using Stata version 11.0 (Stata Corp, College Station, TX, USA).

\section{Results}

Of 1922 outpatients, 1562 (81.2\%) completed the questionnaire and their baseline characteristics and behavioral stages were recorded. Their mean age was $58 \pm 17.3$ years and 977 $(62.5 \%)$ were women. Table 1 summarizes the baseline characteristics of the no salt restriction group $(n=715)$ and the salt restriction group $(n=847)$. With the exception of the desire to undergo genetic testing, all baseline characteristics differed between the two groups.

The behavioral changes following disclosure of the hypothetical genetic test results are shown in Table 2 and Figure 1. In the no salt restriction group, more patients reported progression of behavioral stage following a positive test result than following a negative test result (positive versus negative: 420 [58.7\%] versus 213 [29.8\%]; $P<0.001$ ). In the subgroup analysis of the no salt restriction group, the findings in both the precontemplation and contemplation groups were similar. However, in the preparation group, there was no difference in the number of patients who reported progression of behavioral stage following a positive or negative result. In contrast, in the salt restriction group, more patients stated that they would "quit salt restriction" following a negative result than following a positive test result (negative versus positive: 78 [9.2\%] versus 19 [2.2\%]; $P<0.001)$. In the subgroup analysis of the salt restriction group, the numbers of patients stating that they would "quit salt restriction" differed following a positive or negative result in the maintenance group but not in the action group.

Factors related to an upward trend in behavioral change in the no salt restriction group were age $<65$ years (adjusted OR 1.74; 95\% CI 1.12-2.71), female gender (adjusted OR 1.84; 95\% CI 1.29-2.62), graduation from college or university (adjusted OR 1.66; 95\% CI 1.11-2.49), and desire to undergo genetic testing (adjusted OR 4.53; 95\% CI 3.13-6.57, Table 3).

Table I Baseline characteristics in the no salt restriction and salt restriction groups

\begin{tabular}{|c|c|c|c|c|}
\hline & $\begin{array}{l}\text { Total } \\
(n=1562)\end{array}$ & $\begin{array}{l}\text { Non-salt restriction } \\
(n=7 \mid 5)\end{array}$ & $\begin{array}{l}\text { Salt restriction } \\
(n=847)\end{array}$ & $P$ value* \\
\hline Age, years, mean $\pm S D$ & $58.0 \pm 17.3$ & $51.0 \pm 16.6$ & $64.2 \pm 15.5$ & $<0.001$ \\
\hline Age $(<65$ years $)$ & 935 (59.9) & $555(77.6)$ & $380(44.9)$ & $<0.001$ \\
\hline Women, n (\%) & $977(62.5)$ & $397(55.5)$ & $580(68.5)$ & $<0.001$ \\
\hline Graduation from college or university & $405(26.2)$ & $223(31.2)$ & $182(2 \mid .5)$ & $<0.001$ \\
\hline Family history of hypertension & $598(38.4)$ & $254(35.5)$ & $345(40.7)$ & 0.04 \\
\hline Hypertension & $543(34.8)$ & $150(2 \mid .0)$ & $393(46.4)$ & $<0.001$ \\
\hline Cardiovascular or cerebrovascular disease & $64(4.1)$ & $20(2.8)$ & $44(5.2)$ & 0.02 \\
\hline Anxiety about hypertension & $859(55.4)$ & $343(48.0)$ & $516(60.9)$ & $<0.001$ \\
\hline Salt preference & $945(60.1)$ & $566(79.2)$ & $379(44.7)$ & $<0.001$ \\
\hline Desire to undergo genetic testing & 770 (49.9) & $340(47.6)$ & $430(50.8)$ & 0.21 \\
\hline
\end{tabular}

Notes: $\mathrm{n}(\%)$ except age. *No salt restriction group versus salt restriction group, unpaired $t$-test; age, and Chi-square test; the other items. Abbreviation: SD, standard deviation. 


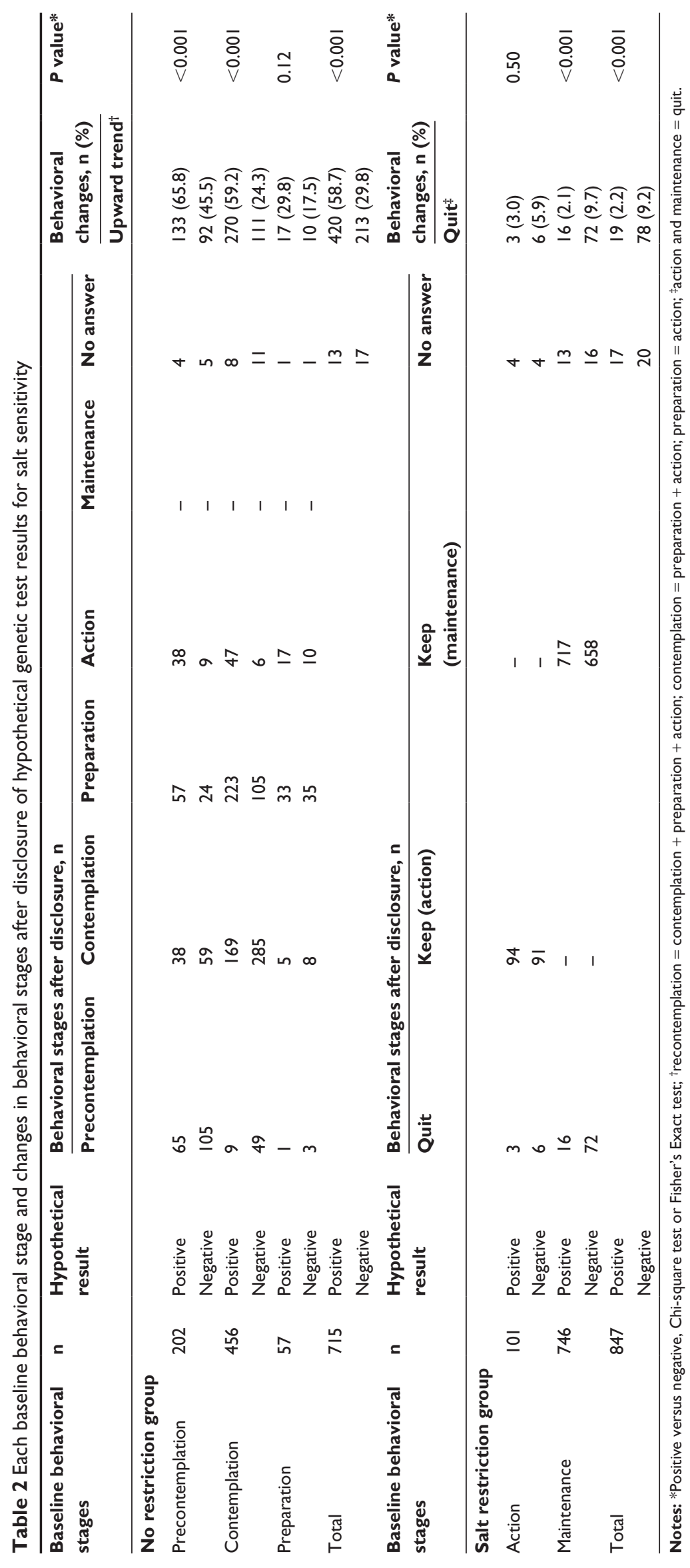



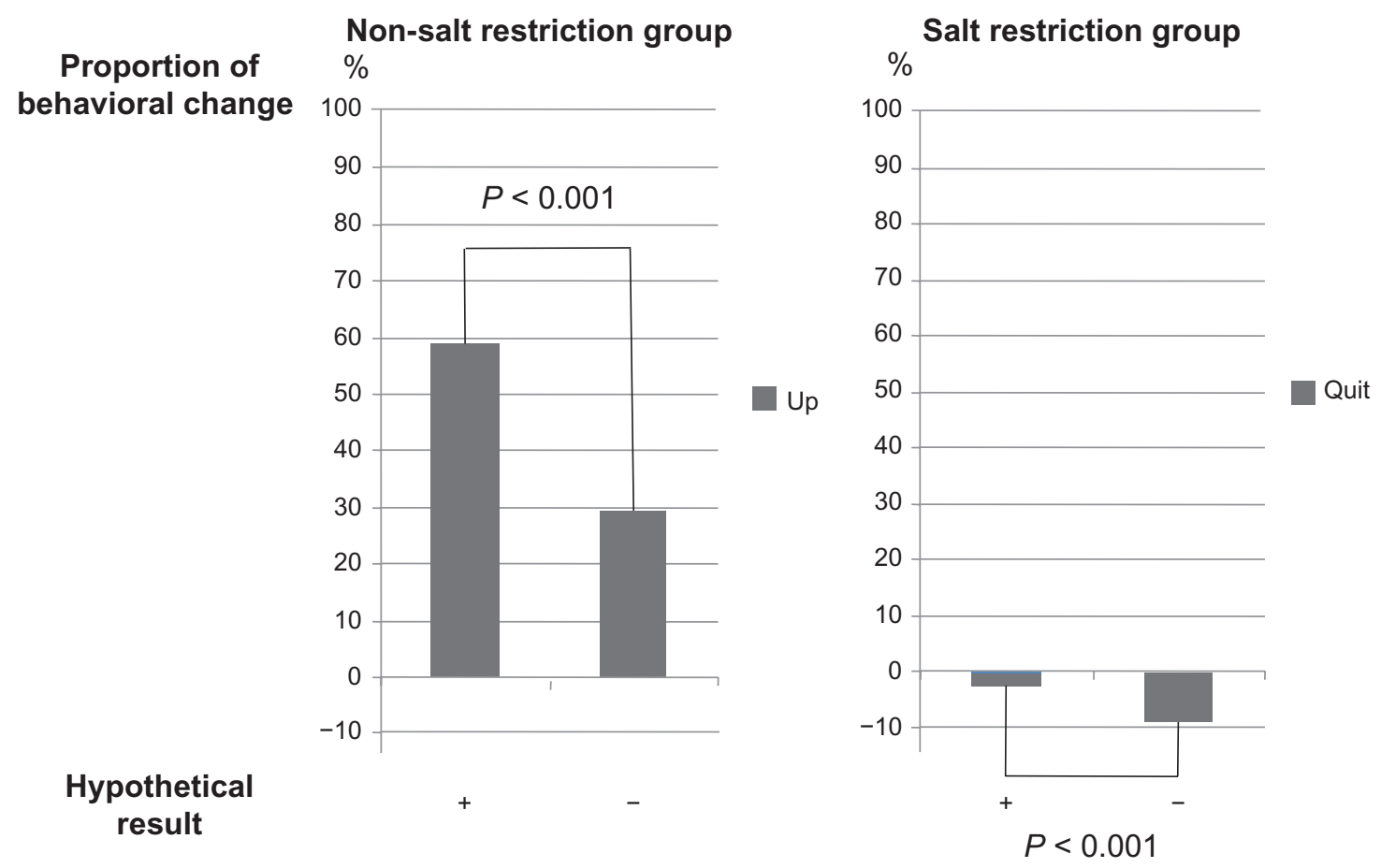

Figure I Behavioral changes as a result of disclosure of hypothetical genetic test results of salt sensitivity showing the proportion of behavioral changes as a result of disclosure of hypothetical results in both the no salt restriction and salt restriction groups.

Notes: In the no salt restriction group, the percentage of outpatients who progressed was $58.7 \%$ if the hypothetical result was positive and $29.8 \%$ if the hypothetical result was negative $(P<0.001$, Chi-square test). Conversely, in the salt restriction group, the percentage of outpatients who stated that they would quit salt restriction was $9.2 \%$ if the hypothetical result was negative and $2.2 \%$ if the hypothetical result was positive $(P<0.00$ I, Chi-square test and Fisher's Exact test).

Conversely, the factor related to a behavioral change of "quit" in the salt restriction group was salt preference (adjusted OR 2.13; 95\% CI 1.31-3.49, Table 4).

\section{Discussion}

We focused on progression of behavioral stage in the no salt restriction group and quitting salt restriction in the salt restriction group. In the transtheoretical model, the progress of the patients' behavioral stages indicated an increase in their motivation to reduce their salt intake. Our findings indicate that disclosing a positive genetic test result for salt sensitivity could motivate individuals who are not currently restricting their salt intake. The disclosure of positive genetic test results related to sensitivity to a lifestyle-related disease may lead

Table 3 Factors related to upward trend in behavioral changes following disclosure of positive results in the no salt restriction group

\begin{tabular}{|c|c|c|c|c|}
\hline & \multirow{2}{*}{$\begin{array}{l}\text { Upward trend } \\
(n=420)\end{array}$} & \multirow{2}{*}{$\begin{array}{l}\text { Non-upward trend } \\
(n=282)\end{array}$} & \multicolumn{2}{|l|}{ OR $(95 \% \mathrm{Cl})$} \\
\hline & & & Univariate analysis & $\begin{array}{l}\text { Multivariate analysis } \\
(n=689)\end{array}$ \\
\hline Age (<65 years) & $346(82.4)$ & $210(74.5)$ & $1.92(1.32-2.79)$ & I.74 (I.I2-2.7I) \\
\hline Women & $255(60.7)$ & 134 (47.5) & I.7I (I.24-2.34) & $1.84(1.29-2.62)$ \\
\hline Graduation from college or university & $158(37.6)$ & $62(22)$ & $2.14(1.50-3.08)$ & $1.66(1.11-2.49)$ \\
\hline Family history of hypertension & $148(35.2)$ & $102(36.2)$ & $0.96(0.69-1.33)$ & \\
\hline Hypertension & 71 (16.9) & $75(26.6)$ & $0.56(0.38-0.82)$ & $0.67(0.42-1.08)$ \\
\hline Cardiovascular or cerebrovascular disease & $8(1.9)$ & $12(4.26)$ & $0.44(0.15-1.18)$ & \\
\hline Anxiety about hypertension & $186(44.3)$ & $150(53.2)$ & $0.70(0.5 I-0.96)$ & $0.69(0.47-1.01)$ \\
\hline Salt preference & $334(79.5)$ & $221(78.4)$ & $\mathrm{I} .07(0.72-\mathrm{I} .57)$ & \\
\hline Desire for undergoing a genetic testing & 251 (59.8) & $88(3 \mid .2)$ & $3.24(2.33-4.52)$ & $4.53(3.13-6.57)$ \\
\hline \multicolumn{5}{|l|}{ Behavioral stages } \\
\hline Precontemplation stage & $133(31.7)$ & $65(23)$ & $1.55(1.08-2.22)$ & $2.18(1.44-3.30)$ \\
\hline Contemplation stage & $270(64.3)$ & 178 (63.1) & $1.05(0.76-1.46)$ & Ref \\
\hline Preparation stage & $17(4.05)$ & $39(13.8)$ & $0.26(0.14-0.49)$ & $0.37(0.22-0.63)$ \\
\hline
\end{tabular}

Abbreviations: OR, odds ratio (upward/nonupward trend); $\mathrm{Cl}$, confidence interval. 
Table 4 Factors related to the quit in behavioral changes following disclosure of negative results in the salt restriction group

\begin{tabular}{|c|c|c|c|c|}
\hline & \multirow{2}{*}{$\begin{array}{l}\text { Quit } \\
(n=78)\end{array}$} & \multirow{2}{*}{$\begin{array}{l}\text { Keep } \\
(n=749)\end{array}$} & \multicolumn{2}{|l|}{ Odds ratio $(95 \% \mathrm{Cl})$} \\
\hline & & & Univariate analysis & $\begin{array}{l}\text { Multivariate analysis } \\
(n=8 \mid 4)\end{array}$ \\
\hline Age ( $<65$ years $)$ & $25(32.1)$ & $350(46.7)$ & $0.54(0.31-0.90)$ & $0.57(0.34-1.02)$ \\
\hline Women & $50(64.1)$ & $521(69.6)$ & $0.78(0.47-1.32)$ & \\
\hline Graduation from college or university & $9(11.5)$ & $17 \mid(22.8)$ & $0.44(0.19-0.91)$ & $0.60(0.28-1.27)$ \\
\hline Family history of hypertension & $28(35.9)$ & $312(4 \mid .7)$ & $0.78(0.46-1.30)$ & \\
\hline Hypertension & $42(53.8)$ & $342(45.7)$ & $1.39(0.85-2.28)$ & \\
\hline Cardiovascular or cerebrovascular disease & $7(8.97)$ & $37(4.94)$ & $1.90(0.69-4.52)$ & \\
\hline Anxiety about hypertension & $47(60.3)$ & $457(6 \mathrm{I})$ & $0.97(0.59-1.63)$ & \\
\hline Salt preference & $48(61.5)$ & $320(42.7)$ & $2.12(1.28-3.55)$ & $2.13(1.31-3.49)$ \\
\hline Desire to undergo genetic testing & $42(53.8)$ & $386(51.5)$ & $1.09(0.67-1.80)$ & \\
\hline \multicolumn{5}{|l|}{ Behavioral stages } \\
\hline Active & $6(7.69)$ & $91(12.1)$ & $0.60(0.25-1.42)$ & Ref \\
\hline Maintenance & $72(92.3)$ & $658(87.9)$ & $1.66(0.70-3.93)$ & $1.77(0.73-4.30)$ \\
\hline
\end{tabular}

Abbreviations: OR, odds ratio (quit/keep); $\mathrm{Cl}$, confidence interval.

individuals to improve their health-seeking behavior. In contrast, those who were already reducing their salt intake might quit restricting salt intake upon disclosure of negative results. In patients with breast cancer, negative $B R C A 1 / 2$ results predicted low levels of anxiety and depression. ${ }^{17}$ Moreover, it is reported that participating in genetic testing, irrespective of the results, reduces patients' level of distress. ${ }^{18}$ However, disclosure of negative genetic test results may not preclude individuals from worrying about lifestyle factors.

Gene polymorphisms related to salt-sensitive hypertension do not contribute greatly to increased blood pressure ${ }^{8,9}$ Further, the strength of the association between gene polymorphisms and hypertension is inconsistent across different studies. However, the effectiveness of salt restriction in the overall population has been established. ${ }^{19}$ Salt restriction is vital in the prevention of hypertension, irrespective of genetic test results. It is unclear whether patients without a genetic risk for salt-sensitive hypertension avoid efforts to reduce salt intake. We suggest that the results of genetic testing can exert relevant positive or negative influences on lifestyle choices, given the recent advances in direct-to-consumer genetic testing.

We also found that a preference for salt is a risk factor for quitting salt restriction in individuals who reduced their salt intake following negative test results. Thus, counseling is important for patients at high risk for cerebrovascular and cardiovascular disease to encourage continuation of salt restriction, even if genetic test results are negative. In the no salt restriction group, age $<65$ years, female gender, academic background, and a desire to undergo genetic testing were factors related to progression of the patients' behavioral stages to the action stage, ie, reducing salt intake, if the genetic test results were positive. Correspondingly, age $>65$ years, male gender, and low education level were factors related to difficulty in reducing salt intake, even if patients were informed of positive genetic test results regarding salt sensitivity. Counseling could be necessary for elderly men who may have difficulty making behavioral changes following disclosure of genetic test results. These patients need more information and support about how and why they should reduce their salt intake. The genetic counselor may also need to use different approaches from those used in younger patients when explaining the nature and meaning of the genetic tests.

\section{Limitations}

This study has several limitations. First, our results are based on hypothetical questions; further trials are required to measure behavioral changes in response to actual genetic test results. Second, we compared differences in behavioral changes following disclosure of positive and negative hypothetical genetic test results; however, comparisons between patients who are informed of their genetic status with those who are not and between those who are informed of salt-sensitivity hypertension-related genetic tests and those unrelated to salt intake or blood pressure would be more valid. Third, the behavioral changes observed in this study indicate the Hawthorne effect. ${ }^{20}$ In the no salt restriction group, $29.8 \%$ reported progression of behavioral stage following negative results. We may have overestimated the $58.7 \%$ reportedly progressing in the no salt restriction group following disclosure of a positive result. Fourth, division of patients into active and maintenance stages by six months has no precedent in salt restriction behavior because the transtheoretical model is constructed on the basis of smoking cessation behavior. In addition, the internal validity of the questions used for assessing the 
patients' behavioral stages of salt intake was not evaluated, although these questions were modified from those authorized by the Japanese government. ${ }^{16}$ Fifth, we selected the baseline characteristics measured in this study on the basis of previous studies that clarified factors related to individuals who were willing to undergo genetic testing. ${ }^{21-24}$ However, it is unknown whether these items are sufficient to evaluate the relationships between genetic factors and behavioral change. Finally, we did not evaluate the effects of disclosure of a hypothetical genetic test result in terms of quality of life, control of hypertension, and prevention of an adverse cardiovascular outcome. Future studies are required to clarify these issues.

\section{Conclusion}

We suggest that disclosure of genetic test results regarding salt sensitivity has both positive and negative effects on salt restriction behavior. Patients in the no salt restriction group have the possibility for progression of behavioral stage to the action stage after testing positive for salt sensitivity. Conversely, patients in the salt restriction group, particularly those with a salt preference, would quit salt restriction after testing negative. Counseling may be important after genetic testing. In the future, it will be necessary to assess behavioral changes using actual test results.

\section{Acknowledgments}

We thank Sachiko Ohguri, Reiko Kobayashi, and Koko Kawabata for their assistance with data collection. This work was supported by a Grant-in-Aid for Scientific Research (B, 21390168) from the Japan Society for the Promotion of Science.

\section{Disclosure}

The authors declare that they have no competing interests in this work.

\section{References}

1. Rafi I, Qureshi N, Lucassen A, et al. 'Over-the-counter' genetic testing: what does it really mean for primary care? $\mathrm{Br} \mathrm{J} \mathrm{Gen} \mathrm{Pract.}$ 2009;59(561):283-287.

2. [No authors listed]. Intersalt: an international study of electrolyte excretion and blood pressure. Results for 24 hour urinary sodium and potassium excretion. Intersalt Cooperative Research Group. BMJ. 1988;297(6644):319-328.

3. Sacks FM, Svetkey LP, Vollmer WM, et al. Effects on blood pressure of reduced dietary sodium and the Dietary Approaches to Stop Hypertension (DASH) diet. DASH-Sodium Collaborative Research Group. $N$ Engl $J$ Med. 2001;344(1):3-10.

4. Kawano Y, Ando K, Matsuura H, et al. Report of the Working Group for Dietary Salt Reduction of the Japanese Society of Hypertension: (1) Rationale for salt restriction and salt-restriction target level for the management of hypertension. Hypertens Res. 2007;30(10):879-886.
5. Kaplan NM. Salt intake, salt restriction, and essential hypertension. Available from: http://www.uptodate.com/contents/salt-intake-saltrestriction-and-essential-hypertension?source $=$ see_link. Accessed March 27, 2013.

6. Tejada T, Fornoni A, Lenz O, Materson BJ. Nonpharmacologic therapy for hypertension: does it really work? Curr Cardiol Rep. 2006;8(6):418-424.

7. Katsuya T, Ishikawa K, Sugimoto K, Rakugi H, Ogihara T. Salt sensitivity of Japanese from the viewpoint of gene polymorphism. Hypertens Res. 2003;26(7):521-525.

8. Bagos PG, Elefsinioti AL, Nikolopoulos GK, Hamodrakas SJ. The GNB3 C825T polymorphism and essential hypertension: a metaanalysis of 34 studies including 14,094 cases and 17,760 controls. J Hypertens. 2007;25(3):487-500.

9. Pereira TV, Nunes AC, Rudnicki M, Yamada Y, Pereira AC, Krieger JE. Meta-analysis of the association of 4 angiotensinogen polymorphisms with essential hypertension: a role beyond M235T? Hypertension. 2008;51(3):778-783.

10. Rollnich S, Mason P, Butler C. Health Behavior Change, a Guide for Practitioners. Edinburgh, Scotland: Churchill Livingstone; 1999.

11. Weinstein ND, Rothman AJ, Sutton SR. Stage theories of health behavior: conceptual and methodological issues. Health Psychol. 1998;17(3):290-299.

12. Kinney AY, Gammon A, Coxworth J, Simonsen SE, Arce-Laretta M. Exploring attitudes, beliefs, and communication preferences of Latino community members regarding BRCA $1 / 2$ mutation testing and preventive strategies. Genet Med. 2010;12(2):105-115.

13. Herbild L, Gyrd-Hansen D, Bech M. Patient preferences for pharmacogenetic screening in depression. Int $J$ Technol Assess Health Care. 2008;24(1):96-103.

14. Smerecnik CM, Mesters I, van Keulen H, et al. Should individuals be informed about their salt sensitivity status? First indications of the value of testing for genetic predisposition to low-risk conditions. Genet Test. 2007;11(3):307-314.

15. Marteau TM, Lerman C. Genetic risk and behavioural change. BMJ. 2001;322(7293):1056-1059.

16. Exploratory committee on standard methods for health-check and health guidance. A questionnaire for evaluating behavioral stages of lifestyle. Available from: http://www.mhlw.go.jp/bunya/kenkou/seikatsu/pdf/03c-06.pdf. Accessed March 27, 2013.

17. Bredart A, Kop JL, Depauw A, et al. Short-term psychological impact of the BRCA1/2 test result in women with breast cancer according to their perceived probability of genetic predisposition to cancer. $\mathrm{Br} \mathrm{J}$ Cancer. 2013;108(5):1012-1020.

18. Jones DL, Clayton EW. The role of distress in uptake and response to predisposition genetic testing: the BMPR2 experience. Genet Test Mol Biomarkers. 2012;16(3):203-209.

19. Bibbins-Domingo K, Chertow GM, Coxson PG, et al. Projected effect of dietary salt reductions on future cardiovascular disease. $N$ Engl J Med. 2010;362(7):590-599.

20. McCarney R, Warner J, Iliffe S, van Haselen R, Griffin M, Fisher P. The Hawthorne effect: a randomised, controlled trial. BMC Med Res Methodol. 2007;7:30.

21. Tambor ES, Rimer BK, Strigo TS. Genetic testing for breast cancer susceptibility: awareness and interest among women in the general population. Am J Med Genet. 1997;68(1):43-49.

22. Bunn JY, Bosompra K, Ashikaga T, Flynn BS, Worden JK. Factors influencing intention to obtain a genetic test for colon cancer risk: a population-based study. Prev Med. 2002;34(6):567-577.

23. Doukas DJ, Localio AR, Li Y. Attitudes and beliefs concerning prostate cancer genetic screening. Clin Genet. 2004;66(5):445-451.

24. Lacour RA, Daniels MS, Westin SN, et al. What women with ovarian cancer think and know about genetic testing. Gynecol Oncol. 2008;111(1):132-136. 


\section{Publish your work in this journal}

The International Journal of General Medicine is an international, peer-reviewed open-access journal that focuses on general and internal medicine, pathogenesis, epidemiology, diagnosis, monitoring and treatment protocols. The journal is characterized by the rapid reporting of reviews, original research and clinical studies across all disease areas.

A key focus is the elucidation of disease processes and management protocols resulting in improved outcomes for the patient. The manuscript management system is completely online and includes a very quick and fair peer-review system. Visit http://www.dovepress.com/ testimonials.php to read real quotes from published authors.

Submit your manuscript here: http://www.dovepress.com/international-journal-of-general-medicine-journal 